УДК 622.276

DOI: $10.31660 / 0445-0108-2019-6-159-166$

Ограничение газопритоков в условиях разработки ботуобинского горизонта

\author{
И. И. Краснов ${ }^{1}$, В. Ф. Томская ${ }^{1}$, Е. И. Инякина ${ }^{2 *}$, К. О. Томский ${ }^{1}$, \\ М. С. Иванова ${ }^{1}$, Р. К. Катанова ${ }^{1}$
}

${ }^{1}$ Мирнинский политехнический институт (филиал) Северо-Восточного федерального университета им. М. К. Аммосова, г. Мирный, Россия

${ }^{2}$ Тюменский индустриальный университет, г. Тюмень, Россия

*e-mail: injakinaei@tyuiu.ru

Аннотащия. В работе изложены результаты изучения геологического строения нефтегазовых залежей ботуобинского горизонта, влияющие на загазовывание добывающих скважин и прорыв газа в нефтяную оторочку в условиях разработки месторождения. В процессе исследований дана характеристика пласта, а также определен расчетным методом оптимальный безгазовый дебит, позволяющий ограничить газоприток для условий эксплуатации Среднеботуобинского нефтегазоконденсатного месторождения. Рассматриваемое месторождение является одним из уникальных кладовых ВосточноСибирского нефтяного кластера, расположенного на территории Республики Саха (Якутия). Обоснованы основные факторы, оказывающие влияние на эффективную выработку запасов нефти газонефтяных залежей в пределах Центрального блока и Курунгского лицензионного участка.

Ключевые слова: ботуобинский горизонт; газоизоляционные работы; прорыв газа; газовая шапка; загазовывание добывающих скважин; предельный безгазовый дебит

\title{
Limitation of gas inflows under the conditions of development of Botuobinsky horizon
}

\author{
Ivan I. Krasnov ${ }^{1}$, Vanessa F. Tomskaya ${ }^{1}$, Ekaterina I. Inyakina ${ }^{2 *}$, \\ Kirill O. Tomsky ${ }^{1}$, Mariya S. Ivanova ${ }^{1}$, Rosalia K. Katanova ${ }^{1}$ \\ ${ }^{1}$ Mirny Polytechnic Institute (branch), M. K. Ammosov North-Eastern Federal \\ University, Mirny, Russia \\ ${ }^{2}$ Industrial University of Tyumen, Tyumen, Russia \\ *e-mail: injakinaei@tyuiu.ru
}

Abstract. The article presents the results of the study of the geological structure of oil and gas deposits in Botuobinsky horizon, affecting the gasification of producing wells and gas breakthrough into the oil rim in the conditions of field development. In the course of the research, a characteristic of the reservoir was given, and the optimal gas-free flow rate was determined by a computational method, which allows us to limit the gas inflow for the operating conditions of the Srednebotuobinskoye oil and gas condensate field. The field under consideration is one of the unique storehouses of the East-Siberian oil cluster located in the Republic of Sakha (Yakutia). The main factors influencing the effective development of oil reserves of gas and oil deposits within the Central block and the Kurung license area are substantiated.

Key words: Botuobinsky horizon; gas insulation works; gas breakthrough; gas cap; gassing of producing wells; maximum gasless flow rate 


\section{Введение}

Эффективность проведения газоизоляционных мероприятий при разработке нефтегазовых залежей ботуобинского горизонта, как и для других месторождений с трудноизвлекаемыми запасами нефти, является важной проблемой уже на ближайшую перспективу. Огромное значение при этом отводится регулированию и контролю процессов выработки запасов нефти, ограничению неэффективной утилизации попутного газа на факел. Оценка перспективы применения методов газоизоляционных работ связана с созданием нетрадиционных технологий, физическая сущность которых отличается не только высокой технологической эффективностью, но и ресурсосбережением с существенным расширением геологических критериев их применимости. Целью работы является выявление основных причин преждевременного прорыва пластового газа из вышележащего газонасыщенного пласта к скважинам, эксплуатирующим нефтяную оторочку с учетом особенности геологического строения ботуобинского горизонта Среднеботуобинского месторождения, расположенного на территории Республики Саха (Якутии).

\section{Проблематика}

Для газонефтяных залежей с любой геологической характеристикой важной проблемой являются совершенствование способов контроля и регулирования процессов пластовой энергии, обеспечение высоких темпов добычи нефти при благоприятных режимах фильтрации и ограничение темпов роста обводненности и загазовывания добывающих скважин. Для осуществления оптимальной безгазовой выработки запасов нефти необходимо определить одновременно предельные дебиты, а также соответствующую предельную депрессию. Актуальным в настоящее время является рассмотрение для конкретных месторождений решений с использованием современных методических подходов к расчету времени безгазовой эксплуатации скважин. Задачи ограничения преждевременного прорыва газа из газовой шапки к забою добывающих скважин, эксплуатирующих нефтенасыщенный пласт с подстилающим водоносным горизонтом, рассматривались многими как отечественными, так и зарубежными исследователями в широком диапазоне применяемых решений [1-3].

Процесс добычи нефти обусловливается понижением давления в призабойной зоне пласта (ПЗП). Поэтому пластовый газ газовой шапки прорывается в интервал перфорации, то есть формируется конус газа. В результате происходит загазовывание скважин, растет газовый фактор до 2 200-3500 м м $^{3}$ м $^{3}$ когда дальнейшая эксплуатация скважины становится нерентабельной. Следствием этого являются снижение отборов нефти из залежи и достижение низкого значения коэффициента нефтеотдачи. В наибольшей степени проблема прорыва газа проявляется в случае месторождений с большой площадью газонефтяного контакта (ГНК). К аспектам данной проблемы относятся следующие способы: установление оптимальных режимов работы скважин; эксплуатация добывающих скважин на предельных безгазовых дебитах; совместный регулируемый отбор нефти и газа при периодической эксплуатации скважин; создание жесткого непроницаемого и динамического газоизоляционных экранов [4-9].

\section{Объект и методы исследования}

Объектом исследования в работе являются газонефтяные залежи ботуобинского горизонта, расположенного на Среднеботуобинском месторождении [10-15]. Рост газового фактора напрямую связан с расположением скважин относительно ГНК, чем ближе скважина к контуру газоносности, тем 
меньше безгазовый период эксплуатации скважин и быстрее происходит подтягивание конуса газа (рис. 1).

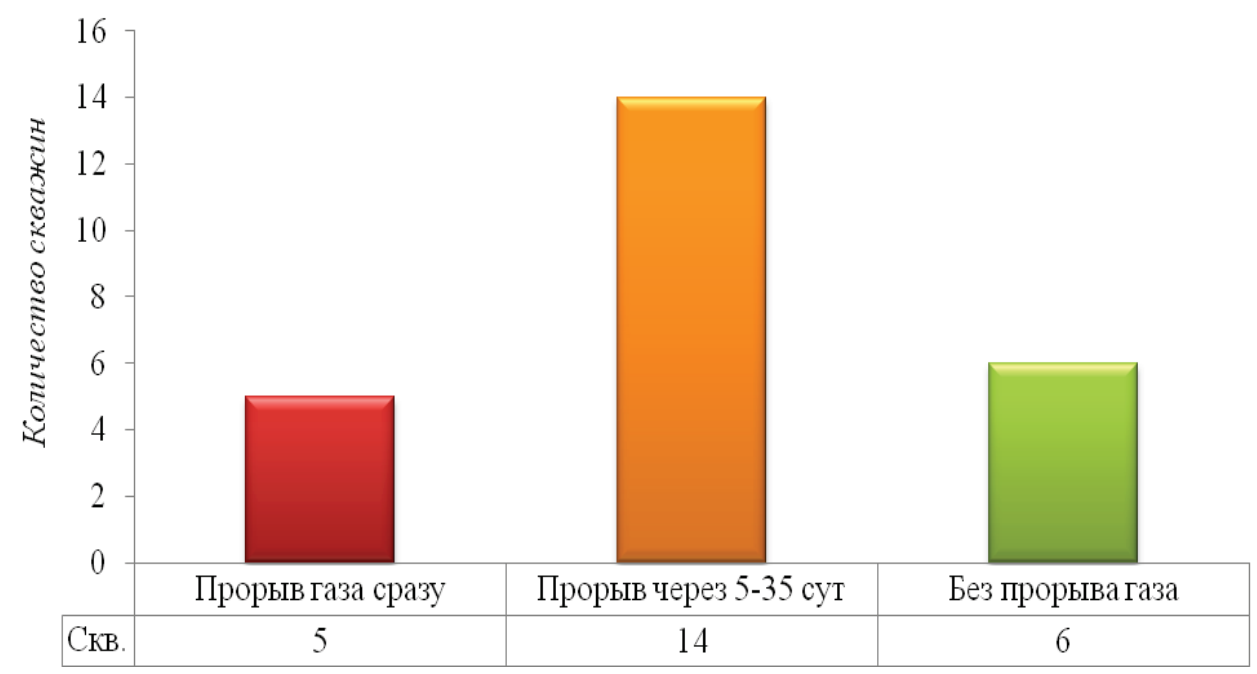

Рис. 1. Распределение скважин по интервалам времени начала прорыва газа

С целью определения оптимального безгазового периода эксплуатации скважин был выполнен расчет по методике Маскета - Чарного для условий Ботуобинского горизонта [16-19].

Предельный безгазовый дебит без экрана

$$
\mathrm{Q}_{\text {пр }}=\frac{\pi \mathrm{k} \Delta \gamma\left(\mathrm{h}_{\mathrm{K}}^{2}-\mathrm{h}_{\mathrm{c}}^{2}\right)}{\mu_{\mathrm{H}} \cdot \ln \left(\frac{\mathrm{r}_{\mathrm{K}}}{\mathrm{r}_{\mathrm{c}}}\right)} .
$$

Предельный безгазовый дебит с экраном

$$
\mathrm{Q}_{\ni К}=\frac{\pi \mathrm{k} \Delta \gamma\left(\mathrm{h}_{\mathrm{K}}^{2}-\mathrm{h}_{\mathrm{c}}^{2}\right)}{\mu_{\mathrm{H}} \cdot \ln \check{r}_{\ni}} .
$$

\section{Результаты}

На основании выполненных расчетов был определен безгазовый период работы нефтедобывающих скважин для условий разработки нефтегазовых залежей Среднеботуобинского месторождения, который составил 17 суток.

Для повышения безгазового дебита был обоснован оптимальный радиус газоизоляционного экрана (рис. 2).

Его протяженность 25 метров позволяет перекрыть предельную зону воронки депрессии. При применении радиального изоляционного экрана в скважинах, эксплуатирующих ботуобинский горизонт, безгазовый дебит может возрасти до $52 \mathrm{~m}^{3} /$ сут. 


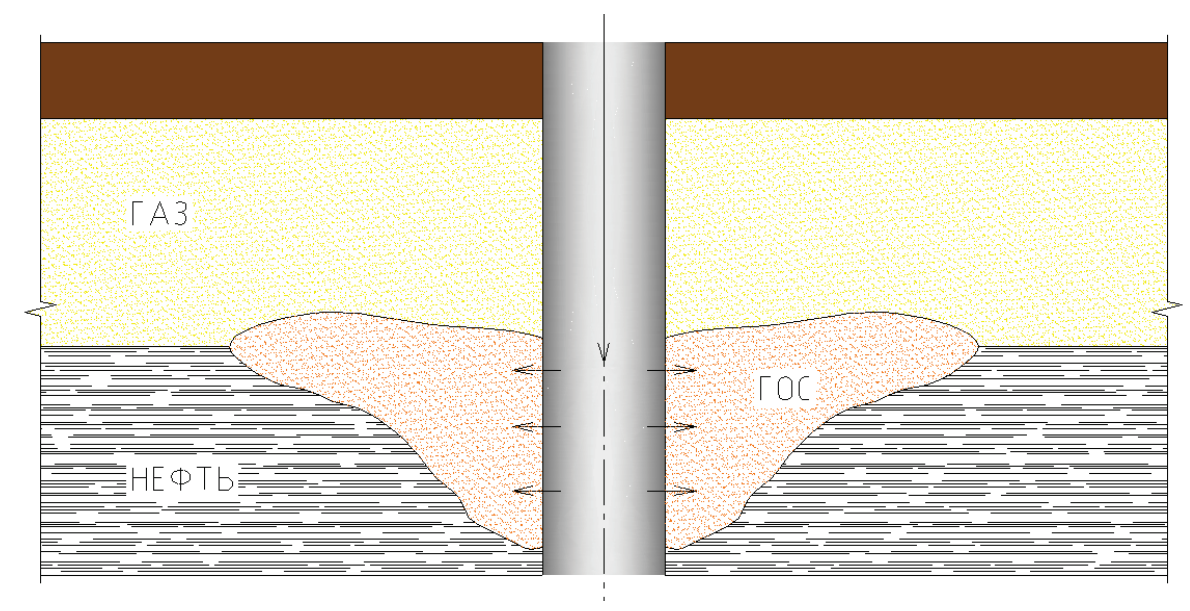

Рис. 2. Схема размещения газоизоляционного экрана

\section{Обсуждение}

Газонефтяная залежь ботуобинского горизонта характеризуется сложным геологическим строением, аномально низкими пластовым давлением и темпе-

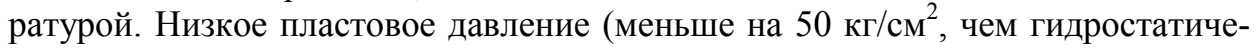
ское) свидетельствует о том, что залежь имеет ограниченный запас пластовой энергии и ее длительная эксплуатация в режиме истощения нецелесообразна.

По результатам промысловых работ, выполненных при разработке Среднеботуобинского месторождения, можно сделать вывод, что геологические условия залегания углеводородов оказывают неблагоприятное влияние на эффективность процесса нефтеизвлечения. Добыча нефти в таких условиях неизбежно сопровождается извлечением значительных объемов попутнодобываемых пластовых вод и прорывом верхнего газа [20-22].
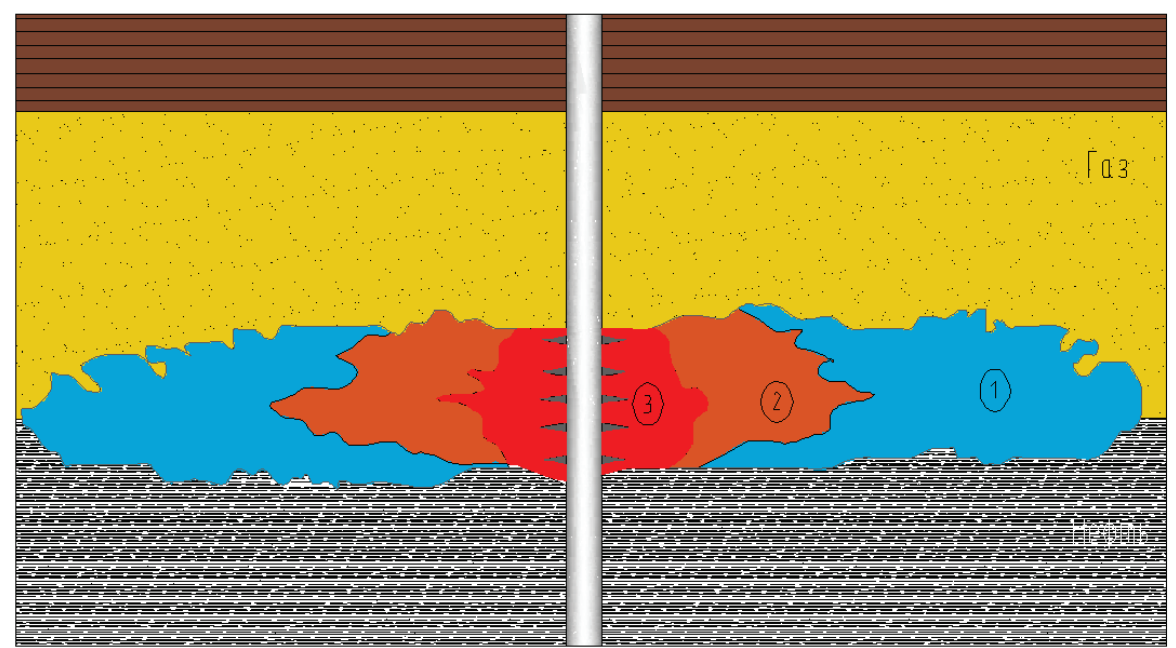

Рис. 3. Блок-схема технологии изоляции газопритоков:

1 - вода $\rightarrow$ водонефттяная эмульсия; 2 - гелеобразующий состав;

3 - закрепляющая композичия 
Из рисунка 3 видно, что установление газоизоляционного экрана, состоящего из воды (1), гелеобразующего состава (2) и закрепляющей композиции (3), на границе раздела газ - нефть позволяет ограничить прорыв газа в нефтенасыщенную область пласта, снизить газовый фактор, уменьшить перепад давления вблизи окрестности ствола скважины и увеличить безгазовый период добычи нефти [23-25].

\section{Выводы}

На основании выполненного анализа опыта разработки газонефтяных залежей с обширной газовой шапкой и тонкой нефтяной оторочкой были определены причины, влияющие на эффективную выработку запасов нефти. Обосновано применение газоизоляционного экрана на участках монолитного строения залежи, то есть при отсутствии на уровне газонефтяного контакта надежных глинистых разделов толщиной менее двух метров.

\section{Библиографический список}

1. Патент на изобретение RUS 2249100. 06.05.2002. Способ интенсификации притоков нефти и газа / Клещенко И. И., Ягафаров А. К., Краснов И. И.

2. Составы для ограничения водопритоков в нефтяные и газовые скважины / И. И. Клещенко [и др.] // Известия высших учебных заведений. Нефть и газ. - 2003. - № 3. - С. 33-37.

3. Исследования напряжений по крепи скважин при воздействии давления горных пород / Д. С. Герасимов [и др.]//Известия высших учебных заведений. Нефть и газ. - 2018. № 5. - C. 89-96. DOI: 10.31660/0445-0108-2018-5-89-96

4. Балуев А. А., Клещенко И. И., Шлеин Г. А. Вскрытие и освоение продуктивных пластов: учеб. пособие. - Тюмень. - 2018. - 211 с.

5. Клещенко И. И., Кузнецов Р. Ю., Сухачев Ю. В. Способ управления водяным конусом при добыче нефти в условиях двухфазной фильтрации // Известия высших учебных заведений. Нефть и газ. - 1998. - № 6. - С. 21-26.

6. Краснов И. И., Островская Т. Д., Матвеева М. В. Особенности выработки трудноизвлекаемых запасов углеводородов на месторождениях Крайнего Севера // Академический журнал Западной Сибири. - 2018. - № 4 (75). - С. 57-59.

7. Томская В. Ф., Инякин В. В., Томский К. О. Особенности выработки запасов нефти на месторождениях Республики Саха (Якутии) // Состояние, тенденции и проблемы развития нефтегазового потенциала Западной Сибири. - Тюмень, 2018. - С. 79-86.

8. Инякина Е. И., Краснов И. И., Инякин В. В. Опыт разработки нефтегазоконденсатных месторождений с осложненной геолого-физической характеристикой // Нефть и газ опыт и инновации. -2017 . - Т. 1, № 1. - С. 41-56.

9. Сивков Ю. В., Краснов И. И. Методы ограничения прорыва газа в нефтедобывающие скважины // Новая наука: от идеи к результату. - 2016. - № 3-1 (72). - С. 33-35.

10. Чарный И. А. Подземная газогидродинамика. - М.: Гостоптехиздат, 1963. - $215 \mathrm{c}$.

11. Результаты изучения пластовых флюидов газонефтяных залежей ботуобинского горизонта / Е. М. Александрова [и др.] // Академический журнал Западной Сибири. - 2018. - № 4 (75). - С. 42-43.

12. Краснов И. И. Экспериментальные исследования свойств кремний содержащей гелеобразующей композиции на основе полиакриламида для условий нефтегазовых месторождений Западной Сибири. // Известия высших учебных заведений. Нефть и газ. - 2002. № 5. - C. $80-84$.

13. Duggan J. O. Estimating Flow Rates Required To Keep Gas Wells Unloaded // Journal of Petroleum Technology. - 1961. - Vol. 13, Issue 12. - P. 1173-1176. DOI: 10.2118/32-PA

14. Bourgeois M. J., Gommard D. R., Gouas H. Simulating early gasbreakthrough in undersaturated oil using alpha-factors // Abu Dhabi International Petroleum Exhibition \& Conference. UAE. - Abu Dhabi, 2012. - P. 214-231. DOI: 10.2118/161460-MS

15. Cavett R. H. Physical Data for Distillation Calculation Vapour-Liquid Equilibria // Proceedings of the Annual API Meeting. - San Francisco, 1964. - P. 351-366. 
16. Experimental Investigation of Critical Condensate Saturation and Its Dependenceon Connate Water Saturation in Water-Wet Rocks / A. Danesh [et al.] // Proceedings: SPE Annual Technical Conference and Exhibition. - USA, Texas, San Antonio, 1989. - Vol. GAMMA. P. 19695669-19695680.

17. Томская В. Ф. Обработка эффективной выработки запасов нефти нефтегазовых залежей Среднеботуобинского НГКМ // IX Всероссийская науч.-практ. конф. студентов, аспирантов и молодых ученых. - М., 2018. - 242 с.

18. Особенности выработки запасов нефти на месторождениях Республики Саха (Якутии) / В. Ф. Томская [и др.] // Состояние, тенденции и проблемы развития нефтегазового потенциала Западной Сибири. - Тюмень, 2018. - С. 79-86.

19. Geological aspects of producing reserves from complex gas deposits / Y. V. Vaganov [et al.] // International Journal of Applied Engineering Research. - 2017. - № 24. - P. 16077-16082.

20. Патент на изобретение. RU 2059064 C1. МПК Е21B 43/32. Способ изоляции газового пласта / Маляренко А. В., Каюмов Р. Ш., Краснов И. И.; заявл.: 15.06.92; опубл.: 27.04.96

21. Краснова Т. Л. Применение жидкостного барьера с целью ограничения прорыва верхнего газа и подошвенной воды в нефтяной пласт и увеличения предельного дебита // Известия высших учебных заведений. Нефть и газ. - 1997. - № 6. - С. 27.

22. Методы и водоизолирующие композиции для производства РИР в нефтяных и газовых скважинах / П. С. Демичев [и др.] // Инновационные технологии для нефтегазового комплекса. - Тюмень, 2010. - С. 103-106.

23. Леонтьев Д. С., Клещенко И. И., Бакин Д. А. Обоснование и разработка технологии создания водоизоляционного экрана в нефтедобывающей скважине // Известия высших учебных заведений. Нефть и газ. - 2018. - № 2. - С. 50-54. DOI: 10.31660/0445-0108-2018-2-50-54

24. Оценка эффективности разработки нефтегазовых залежей Среднеботуобинского месторождения / Е. И. Инякина [и др.] // Научный форум. Сибирь. - 2018.- Т. 4, № 1. - С. 26-28.

25. Краснов И. И. Совершенствование технологии ограничения прорыва верхнего газа в скважины, дренирующие нефтяной пласт // Известия высших учебных заведений. Нефть и газ. -2002 . - № 4. - C. 17-18.

\section{References}

1. Kleshchenko, I. I., Yagafarov, A. K., Krasnov, I. I. Sposob intensifikatsii pritokov nefti i gaza. Patent na izobreteniye RUS 2249100. 06.05.2002. (In Russian).

2. Kleshchenko, I. I., Yagafarov, A. K., Geykhman, M. G., Panikarovskii, V. V. (2003). Sostavy dlya ogranicheniya vodopritokov v neftyanyye i gazovyye skvazhiny. Oil and Gas Studies, (3), pp. 33-37. (In Russian).

3. Gerasimov, D. S., Ovchinnikov ,V. P., Kuznetsov, V. G., Ovchinnikov, P. V., Kleshchenko, I. I., \& Spasibov, V. M. (2018). Study of stresses on the crepe of wells under rocks pressure. Oil and Gas Studies, (5), pp. 89-96. (In Russian). DOI: DOI: 10.31660/0445-0108-2018-5-89-96

4. Baluyev, A. A., Kleshchenko, I. I., Shlein, G. A. (2018). Vskrytiye i osvoyeniye produktivnykh plastov. Tyumen, 211 p. (In Russian).

5. Kleshchenko I. I., Kuznetsov, R. Yu., \& Sukhachev, Yu. V. (1998). Sposob upravleniya vodyanym konusom pri dobyche nefti v usloviyakh dvukhfaznoy fil'tratsii. Oil and Gas Studies, (6), pp. 21-26. (In Russian).

6. Krasnov, I. I., Ostrovskaya, T. D., \& Matveyeva, M. V. (2018). Osobennosti vyrabotki trudno-izvlekayemykh zapasov uglevodorodov na mestorozhdeniyakh Kraynego Severa. Academic Journal of West Siberia, (4(75)), pp. 57-59. (In Russian).

7. Tomskaya, V. F., Inyakin, V. V., \& Tomskiy, K. O. (2018). Osobennosti vyrabotki zapasov nefti na mestorozhdeniyakh Respubliki Sakha (Yakutii). Sostoyaniye, tendentsii i problemy razvitiya neftegazovogo potentsiala Zapadnoy Sibiri. Tyumen, pp. 79-86. (In Russian).

8. Inyakina, E. I., Krasnov, I. I., \& Inyakin, V. V. (2017). Experience of development of oil and gas concrete deposits with complicated geological physical characteristics. Petroleum and gas: experiens and innovation, 1(1), pp. 41-56. (In Russian).

9. Sivkov, Yu. V., \& Krasnov, I. I. (2016). Metody ogranicheniya proryva gaza v neftedobyvayu-shchiye skvazhiny. Novaya nauka: ot idei k rezul'tatu, (3-1(72)), pp. 33-35. (In Russian). 
10. Charnyy, I. A. (1963). Podzemnaya gazogidrodinamika. Moscow, Gostoptekhizdat Publ., 215 p. (In Russian).

11. Aleksandrova, E. M., Inyakina, E. I., Krasnov, I. I., Vaganov, E. V. (2018). Rezul'taty izucheniya plastovykh flyuidov gazoneftyanykh zalezhey botuobinskogo gorizonta. Academic Journal of West Siberia, (4(75)), pp. 42-43. (In Russian).

12. Krasnov, I. I. (2002). Eksperimental'nyye issledovaniya svoystv kremniy soderzhashchey geleobrazuyushchey kompozitsii na osnove poliakrilamida dlya usloviy neftegazovykh mesto-rozhdeniy Zapadnoy Sibiri. Oil and Gas Studies, 5, pp. 80-84. (In Russian).

13. Duggan, J. O. (1961). Estimating Flow Rates Required To Keep Gas Wells Unloaded. Journal of Petroleum Technology, 13(12), pp. 1173-1176. (In English). DOI: 10.2118/32-PA

14. Bourgeois, M. J., Gommard, D. R., \& Gouas, H. (2012). Simulating early gasbreakthrough in undersaturated oil using alpha-factors. Abu Dhabi International Petroleum Exhibition \& Conference. UAE. Abu Dhabi, pp. 214-231. (In English). DOI: 10.2118/161460-MS

15. Cavett, R. H. (1964). Physical Data for Distillation Calculation Vapour-Liquid Equilibria. Proceedings of the Annual API Meeting. San Francisco, pp. 351-366. (In English).

16. Danesh, A., Henderson, G. D., Peden, J. M., \& Heriot-Watt, U. (1989). Experimental Investigation of Critical Condensate Saturation and Its Dependenceon Connate Water Saturation in Water-Wet Rocks. Proceedings: SPE Annual Technical Conference and Exhibition. Vol. GAMMA. USA, Texas, San Antonio, pp. 19695669-19695680. (In English).

17. Tomskaya, V. F. (2018). Obrabotka effektivnoy vyrabotki zapasov nefti neftegazovykh zalezhey Srednebotuobinskogo NGKM. IX Vserossiyskaya nauchno-prakticheskaya konferentsiya studentov, aspirantov i molodykh uchenykh. Moscow, 242 p. (In Russian).

18. Tomskaya, V. F., Inyakin, V. V., Tomskiy, K. O., Krasnov, I. I. (2018). Osobennosti vyrabotki zapasov nefti na mestorozhdeniyakh Respubliki Sakha (Yakutii). Sostoyaniye, tendentsii i problemy razvitiya neftegazovogo potentsiala Zapadnoy Sibiri. Tyumen, pp. 79-86. (In Russian).

19. Vaganov, Y. V., Yagafarov, A. K., Kleshchenko, I. I., Parfiriev, V. A., \& Popova, Z. S. (2017). Geological aspects of producing reserves from complex gas deposits. International Journal of Applied Engineering Research, (24), pp. 16077-16082. (In English).

20. Malyarenko, A. V., Kayumov, R. Sh., Krasnov, I. I. Sposob izolyatsii gazovogo plasta. Patent na izobreteniye. RU 2059064 C1. MPK E21B 43/32. Applied: 15.06.92. Published: 27.04.96. (In Russian).

21. Krasnova, T. L. (1997). Primeneniye zhidkostnogo bar'yera s tsel'yu ogranicheniya proryva verkhnego gaza i podoshvennoy vody v neftyanoy plast i uvelicheniya predel'nogo debita Oil and Gas Studies, (6), pp. 27. (In Russian).

22. Demichev, P. S. (2010). Metody i vodoizoliruyushchiye kompozitsii dlya proizvodstva RIR v neftyanykh i ga-zovykh skvazhinakh. Innovatsionnyye tekhnologii dlya neftegazovogo kompleksa. Tyumen, pp. 103-106. (In Russian).

23. Leontiev, D. S., Kleshchenko, I. I., Bakin, D. A. (2018). Reasoning and development of technology for building a water shut-off screen in oil well. Oil and Gas Studies, (2), pp. 50-54. (In Russian).

24. Inyakina, E. I., Tomskaya, V. F., Shavaleyeva, A. A., \& Varlamov, V. V. (2018). Otsenka effektivnosti razrabotki neftegazovykh zalezhey Srednebotuobinskogo mestorozhdeniya. Scientific forum. Siberia, 4(2), pp. 26-28. (In Russian).

25. Krasnov, I. I. (2002). Sovershenstvovaniye tekhnologii ogranicheniya proryva verkhnego gaza v skvazhiny, dreniruyushchiye neftyanoy plast. Oil and Gas Studies, (4), pp. 17-18. (In Russian).

\section{Сведения об авторах}

Краснов Иван Игнатьевич, к. т. н., доцент кафедры нефтегазового дела, Мирнинский политехнический институт (филиал) Северо-Восточного федерального университета им. М. К. Аммосова, г. Мирный

Томская Ванесса Федоровна, студент, Мирнинский политехнический институт (филиал) Северо-Восточного федерального университета, г. Мирный

\section{Information about the authors}

Ivan I. Krasnov, Candidate of Engineering, Associate Professor at the Department of Oil and Gas Business, Mirny Polytechnic Institute (branch), M. K. Ammosov North-Eastern Federal University, Mirny

Vanessa F. Tomskaya, Student, Mirny Polytechnic Institute (branch), M. K. Ammosov North-Eastern Federal University, Mirny 
Инякина Екатерина Ивановна, к. т. н., дочент кафедры разработки и эксплуата циии нефтяных и газовых месторождений, Тюменский индустриальный университет, 2. Тюмень, e-mail: injakinaei@tyuiu.ru

Томский Кирилл Олегович, к. т. н., доцент, заведуюший кафедрой нефтегазового дела, Мирнинский политехнический институт (филиал) Северо-Восточного феде рального университета им. М. К. Аммосова, 2. Мирный

Иванова Мария Сергеевна, к. М. н., доичент кафедры нефтегазового дела, Мирнинский политехнический институт (филиал) Северо-Восточного федерального университета им. М. К. Аммосова, г. Мирный

Катанова Розалия Кирилловна, лаборант кафедры нефтегазового дела, Мирнинский политехнический институт (филиал) Северо-Восточного федерального университета им. М. К. Аммосова, г. Мирный
Ekaterina I. Inyakina, Candidate of Engineering, Associate Professor at the Department of Development and Operation of Oil and Gas Fields, Industrial University of Tyumen, e-mail: injakinaei@tyuiu.ru

Kirill O. Tomsky, Candidate of Engineering, Associate Professor, Head of the Department of Oil and Gas Business, Mirny Polytechnic Institute (branch), M. K. Ammosov NorthEastern Federal University, Mirny

Mariya S. Ivanova, Candidate of Engineering, Associate Professor at the Department of Oil and Gas Business, Mirny Polytechnic Institute (branch), M. K. Ammosov North-Eastern Federal University, Mirny

Rosalia K. Katanova, Laboratory Assistant at the Department of Oil and Gas Business, Mirny Polytechnic Institute (branch), M. K. Ammosov North-Eastern Federal University, Mirny 